\title{
Cenário do uso educacional de redes sociais na região metropolitana de Porto Alegre/RS
}

\author{
Márcio Roberto Machado da Silva - PPGECIM-ULBRA - marciorms@gmail.com \\ Marlise Geller - PPGECIM-ULBRA - marlise.geller@gmail.com
}

\begin{abstract}
Resumo
As redes sociais estão presentes nos dias de hoje em diferentes seguimentos da sociedade, contudo, essa realidade não se reflete totalmente em sala de aula. Este artigo apresenta reflexões sobre um cenário do uso educacional de redes sociais na região metropolitana de Porto Alegre/RS, baseado em pesquisa realizada com 1.027 alunos e 65 professores, através de questionários e entrevistas semiestruturadas. Para a análise dos dados coletados, utilizou-se o paradigma qualiquantitativo de investigação, apresentando reflexões sobre o perfil dos alunos, professores e diretores de escolas em relação ao uso de redes sociais na educação, aspectos positivos e principais entraves para o uso educacional das redes sociais.
\end{abstract}

Palavras-chave: redes sociais na educação; cibercultura; ciberespaço

\begin{abstract}
Social networks are present nowadays in different segments of society, however, this reality is not reflected fully in the classroom. This paper presents reflections on a scenario of the educational use of social networks in the metropolitan region of Porto Alegre/RS, based on research conducted with 1,027 students and 65 teachers through questionnaires and semi-structured interviews. For the analysis of the collected data, we used the paradigm qualiquantitativo research, presenting reflections on the profile of students, teachers and school principals regarding the use of social networking in education, positive aspects and major obstacles to the educational use of social networks.
\end{abstract}

Keywords: social networks in education; cyberculture; cyberspace

\section{O cenário da investigação}

Pesquisas como Barbosa (2013) e IBOPE (2011) atestam o crescimento do acesso às redes sociais no Brasil, inclusive nas classes sociais menos privilegiadas. IBOPE (2011) verificou que em março de 2011 o Brasil apontou um alcance das redes sociais de 85,6\% dos internautas ativos no trabalho e residência, sendo essa a maior penetração das redes sociais no mundo.

Contudo, quando investigado o tipo de atividade realizada na internet, dentre cinco atividades: comunicação, busca de informações, lazer, educação e serviços financeiros, Barbosa (2013) destaca que a educação, desde 2008 até hoje, ocupou a penúltima colocação.

Enquanto Barbosa (2013) aponta a comunicação como a atividade mais realizada pelos internautas, com 89\% no ano de 2012, a educação ficou com apenas 59\%. Frente a esses dados, surgiu a questão que norteou esta investigação: se temos uma grande penetração de redes sociais, como isso se reflete na educação?

E desta forma, o objetivo deste artigo é apresentar reflexões sobre o cenário do uso de redes sociais na educação, na região metropolitana de Porto Alegre/RS.

Para perseguir o objetivo e construir respostas à questão norteadora, foi utilizada uma perspectiva qualiquantitativa tendo em vista a diversidade de sujeitos envolvidos, a 
necessidade de entendimento dos hábitos e comportamento desses sujeitos em relação ao uso de internet e de redes socais na educação, a necessidade de compreender aspectos que influenciam direta ou indiretamente o uso (ou não uso) de redes sociais nos ambientes escolares e a necessidade de compreender o contexto das escolas em relação à Tecnologia da Informação e Comunicação (TIC).

Visando compreender o cenário da investigação, inicialmente foi realizado um estudo teórico acerca da história e dos conceitos das redes sociais, incluindo dados estatísticos que demonstram os hábitos dos internautas e o tipo de uso das TIC, assim como a evolução da mesma.

Para conhecer os hábitos dos sujeitos desta pesquisa (alunos e professores da região metropolitana de Porto Alegre/RS) em relação ao uso de internet e de redes sociais na educação, incluindo fatores que facilitam e que dificultam o uso das redes sociais como ferramenta pedagógica, foram realizadas a aplicação de questionários a alunos e professores.

O questionário dos alunos foi aplicado presencialmente, no ambiente de aula, por professores, diretores e pelo pesquisador, sendo que de 2.500 exemplares, obteve-se um retorno de 1.027 questionários válidos, envolvendo alunos do Ensino Fundamental e Médio, oriundos de 48 turmas de 7 escolas da região metropolitana de Porto Alegre/RS.

Tabela 1: Distribuição de alunos por faixa de idade e gênero

\begin{tabular}{|c|c|c|}
\hline Faixa de idade & Quant & Percentual \\
\hline De 14 a 16 anos & 638 & $62 \%$ \\
\hline De 17 a 19 anos & 194 & $19 \%$ \\
\hline De 11 a 13 anos & 156 & $15 \%$ \\
\hline Idade não informada & 25 & $2 \%$ \\
\hline Mais de 19 anos & 14 & $1 \%$ \\
\hline Total & 1.027 & $\begin{array}{ll}\text { Feminino } & 56 \% \\
\text { Masculino } & 44 \%\end{array}$ \\
\hline
\end{tabular}

O questionário dos professores foi aplicado tanto presencialmente quanto por meio de formulário eletrônico, disponibilizado no site do autor e divulgado através das redes sociais Facebook e Twitter, onde se obteve 65 questionários válidos, incluindo os questionários impressos, aplicados presencialmente. Desses 65 questionários válidos, 38 são da região metropolitana de Porto Alegre.

Os questionários, tanto de professores quanto de alunos, continham questões, em sua maioria, fechadas, sendo que o questionário dos alunos apresentou uma questão aberta indagando sobre quais ferramentas eram utilizadas pelos professores, e outra com sugestão sobre como utilizar as redes sociais no ensino. Já o questionário dos professores apresentou uma questão aberta sobre sugestão de conteúdos que poderiam ser abordados através das redes sociais. Contudo, essas questões abertas foram pouco respondidas tanto pelos professores quanto pelos alunos.

Visando possibilitar uma análise mais aprofundada e complementar a análise quantitativa feita através dos questionários, foram realizadas entrevistas presenciais semiestruturadas a professores e diretores de escolas.

Os diretores das escolas entraram como sujeitos da pesquisa em função de suas posições estratégicas nas escolas, possuindo informações acerca da infraestrutura disponível e até mesmo por conhecerem a história da escola em se tratando de experiências no uso de TIC e redes sociais pelos professores. Além do que nesta pesquisa, os diretores também são professores.

\section{Educação, Cibercultura e Redes Sociais}

Há muito tempo falamos em sociedade virtual, em ciberespaço, cibercultura, ciberdemocracia, cibridismo e outros temos que se relacionam com um novo modelo de 
sociedade, já não mais tão nova, onde a tecnologia está maciçamente inserida (LÉVY, 1996, 1998 e 1999; CASTELLS, 1999 e 2003; DEGENNE e FORSÉ, 1999; DONATH, 1999; GABRIEL, 2013; FRANCO, 2008b; LEMOS, 2002; LEMOS e LÉVY, 2010; LLORENS e CAPDEFERRO, 2011; MACHADO e TIJIBOY, 2005; MAZMAN e USLUEL, 2009; PATRÍCIO e GONÇALVES, 2010; PECHI, 1011; PRETTO e ANDRADES, 2002; RECUERO, 2009; 2009b; WERHMULLER e SILVEIRA, 2012).

O ciberespaço é o espaço criado e utilizado pelas comunidades mediadas por computador, também chamado de universo das redes digitais, como um espaço de novas fronteiras econômicas e sociais, um terreno de conflitos mundiais. (LÉVY, 2000).

Ou seja, o ciberespaço pode ser definido, seguido a ideia de Lévy (2000) como um universo virtual onde atuam as redes de computadores, principalmente a internet, o qual é aberto, fluido, extremamente conectável, com constante construção e reconstrução, moldado em função dos interesses, dispositivos e tecnologias e suas necessidades.

Este ciberespaço, que coexiste com o ambiente social tradicional em que vivemos, o não virtual, acaba por possibilitar novas formas de comunicação, de socialização, de presença, seja atual ou virtual, novas possibilidades, novas estruturas sociais - a cibercultura.

Esta cibercultura comporta o surgimento de novas formas sociais como comunidades virtuais de aprendizagem, amigos virtuais, seguidores, hackers, crackers, criminosos virtuais, novas formas de bullying, pedofilia, invasão de privacidade e outras expressões culturais.

Nesta sociedade paralela, que coexiste com a sociedade tradicional, o centro não é nem o homem, nem o computador. Estes são apenas mais um nó na rede. Rede com infinitas possibilidades, configurações, funcionalidades, objetivos, penetrações, tamanhos e formatos.

Cabe à cibercultura e ao ciberespaço, o desafio de suportar o caos. Suportar as infinitas formas de interação, de organização, diversidades culturais e tecnológicas.

Neste cenário, nos deparamos com uma sociedade que não dissocia sua presença no espaço convencional ao ciberespaço, precisando coexistir nos dois. Tendo presença ou atuações tanto no presencial, quanto no virtual. O ‘cyber' unindo-se com o 'híbrido', formando o cibridismo, que também pode significar a expansão do ser humanos além do seu corpo biológico, coexistindo nos mundos on-line e off-line, os mundos físico e digital, ao mesmo tempo. (GABRIEL, 2013).

De acordo com Lévy (1999), quanto mais pessoas tiverem acesso ao ciberespaço, mais se desenvolverão novas formas de sociabilidade. Maior será o grau de interação, de compartilhamento e de apropriação de informações pelos diferentes atores.

E essa globalização ou universalização não gera massificação dominadora, pelo contrário, quanto mais universal, menos totalitário. Mais participativo, inclusivo, pluralista, construindo saberes de forma colaborativa com os participantes, atores desta grande rede - o ciberespaço. (LÉVY, 1999).

Porém, não adianta os professores terem acesso às tecnologias se eles não tiverem familiarizados e capacitados para uso dela. A internet e a tecnologia educacional em geral só são vantajosas quando os professores se mostram preparados. Sob esse aspecto, geralmente há uma demora considerável entre o investimento em tecnologia por um lado, e o investimento na formação de educadores por outro. (CASTELLS, 2003).

Por sua vez, frente ao uso das redes sociais e das TIC, o professor deixa de ser um simples fornecedor direto de conhecimento, e passa a ser um animador da inteligência coletiva em rede, favorecendo tanto as aprendizagens personalizadas quanto a aprendizagem coletiva. (LÉVY, 1999). 
Castells (1999, p.36) diz que comunidade virtual é como “uma rede eletrônica de comunicação interativa auto definida, organizada em torno de um interesse ou finalidade compartilhados, embora algumas vezes a própria comunicação se transforme no objetivo”.

Desta forma, a interação é um elemento que necessariamente deve estar presente neste tipo de rede, sendo que, desta forma, e as mídias sociais são as ligações ou interações, ou seja, os meios com que as pessoas (sociedade) se comunicam. (CASTELLS, 1999; RHEINGOLD, 1996; RECUERO, 2009).

O termo "redes sociais", após o advento das tecnologias da informação e da internet, teve adaptações em seu significado, sem perder sua origem, mas permitindo ampliar sua visão para dar conta dos diversos tipos de redes, atores e conexões possíveis, a partir do surgimento da internet, e intensificado pela criação da web 2.0 (AGUIAR, 2006; CASTELLS, 1999; DEGENNE e FORSÉ, 1999; GABRIEL, 2013; LÉVY, 1999, MACHADO, 2005; MAZMAN e USLEUEL, 2009; PATRICIO e GONÇALVES, 2010b; RECUERO, 2009; WERHMULLER e SILVEIRA, 2012).

E do ponto de vista mais relacionado ao social, Castells (1999) descreve uma rede social como um sistema aberto e altamente dinâmico, suscetível de inovação, sem ameaças ao seu equilíbrio.

\section{Percepções e Reflexões}

A partir das análises dos questionários aplicados aos professores e alunos, e das entrevistas semiestruturadas realizadas com professores e diretores constatou-se os aspectos indicados a seguir.

Em termos de acesso à internet, a pesquisa apontou que menos de $1 \%$ dos sujeitos não tem acesso à internet e $86 \%$ tem acesso à internet em suas residências, enquanto apenas 22\% dos alunos tem acesso à internet na escola.

E em se tratando de perfil nas redes sociais, a pesquisa aponta que $87 \%$ dos alunos utilizam a rede social Facebook, sendo que é a ferramenta que apresentou maior uso diário, com $67 \%$ dos alunos, e $20 \%$ dos alunos com uso eventual.

A pesquisa também aponta que apenas 18\% (189 alunos) dos alunos informaram que seus professores utilizam redes sociais como apoio ao ensino.

Em relação ao tipo de uso das redes sociais, foram pesquisados quatro tipos de utilização: comunicação, pesquisas, relacionamento e diversão, onde podemos notar que hoje, o maior uso das redes sociais pelos alunos, é para comunicação. E essa primazia da comunicação como utilização mais frequente nas redes sociais pelos alunos também foi evidenciada em Barbosa (2013).

De forma geral, considerando os quatro tipos de utilização previstos na pesquisa, a ferramenta que apresentou maior versatilidade em termos de tipos de utilização foi o Facebook.

Em termos de professores, foram pesquisados 65 professores, sendo que, desses, 38 lecionam na região metropolitana de Porto Alegre, que apresentaram diversas semelhanças em termos de perfil, à partir das respostas, com o total de professores, evidenciado através do desvio padrão baixo (entre 1\% e 8\%), calculado para cada questão.

Um fator que pode influenciar muito no uso de redes sociais é o fato do professor ter acesso a internet em sua residência e na própria escola, e neste sentido, a pesquisa apontou que $97 \%$ dos professores da região metropolitana de Porto Alegre possuem acesso à internet em sua residência, 61\% acessa a internet na escola e $42 \%$ deles têm acesso à internet através de celular/smartphone. 
Outro dado relevante abordado na pesquisa foi saber em quais redes sociais os professores tem perfil, e foi identificado que 92\% dos professores da região metropolitana de Porto Alegre possuem perfil no Facebook.

Figura 1: Gráfico das 6 ferramentas mais utilizadas pelos alunos somando os tipos de usos (completude)

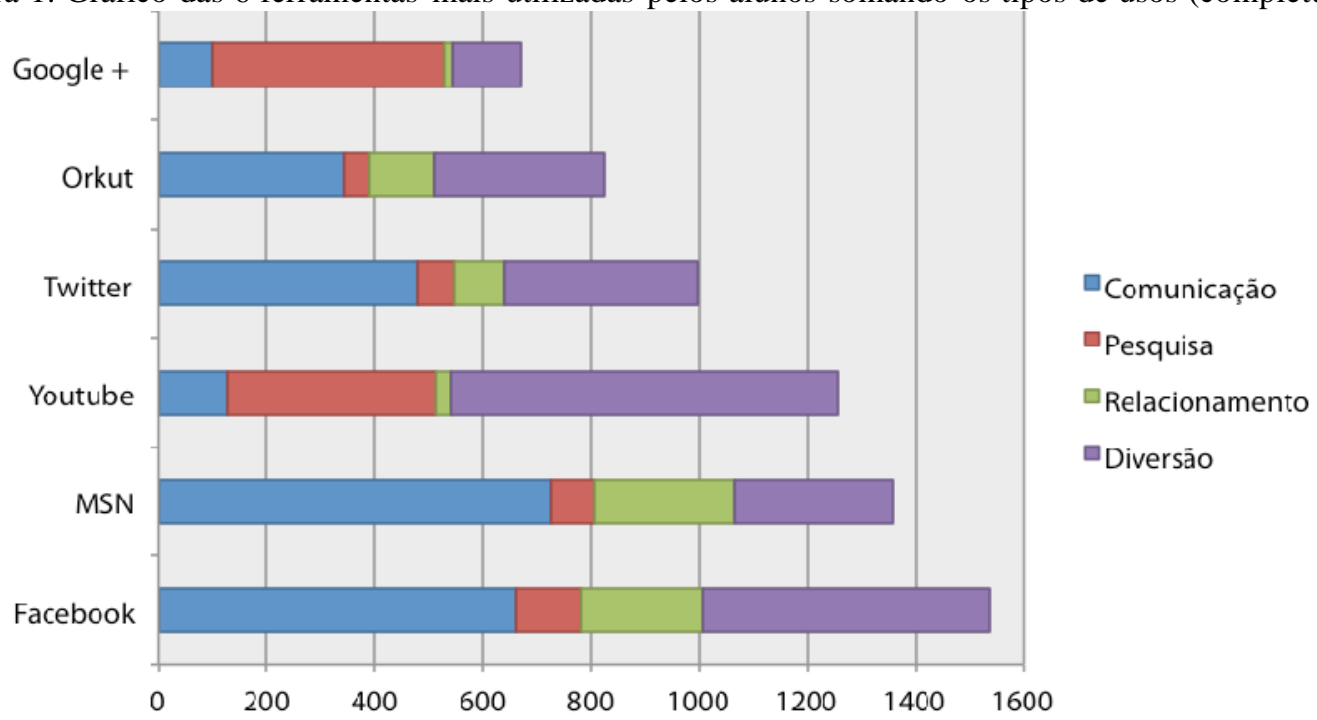

Enquanto isso, a pesquisa também detectou que $74 \%$ dos professores da região metropolitana utilizam as redes sociais para atividades tanto pessoais quanto profissionais, e $24 \%$ usa somente para atividades pessoais. Nesta mesma pesquisa, apenas um professor não marcou nenhuma opção.

Em termos de frequência com que os professores acessam as redes sociais, 82\% dos professores da região metropolitana de Porto Alegre o fazem diariamente, 16\% eventualmente e um professor deixou a questão em branco.

Quando questionados sobre a finalidade do uso das redes sociais, 89\% dos professores respondeu que usa as redes sociais para conversas pessoais, $76 \%$ como fonte de informação, 63\% para conversas profissionais, 53\% para divulgação de conteúdos educativos e $45 \%$ para troca de materiais com alunos e colegas.

Contudo, essas informações não foram refletidas nem nas respostas dos alunos nem nas entrevistas realizadas com professores e diretores das escolas.

Outro ponto importante do questionário foi em relação a aspectos negativos, considerados como limitações para o uso de redes sociais na educação, conforme apresentado na Figura 2.

Sobre este tema, 71\% dos professores julgam importante ou muito importante a falta de tempo dos professores, considerando que o uso de TIC requer dedicação e tempo para preparar e acompanhar as atividades.

Quando o assunto é falta de privacidade, 66\% dos professores acreditam ser este tema importante ou muito importante.

Em se tratando de falta de domínio da rede social, 56\% dos professores acredita ser este tema importante ou muito importante como entrave para o uso de redes sociais na educação.

Relacionado à infraestrutura, quando questionados sobre a importância da dificuldade de acesso às redes sociais na escola, 61\% dos professores julgaram este fator como importante ou muito importante.

Outro aspecto bastante relevante para esta pesquisa foi o questionamento da importância da possibilidade das redes sociais não combinarem com atividades pedagógicas. Neste sentido, $24 \%$ dos professores acreditam que este ponto seja importante ou muito importante. Ou seja, a maioria dos professores não comunga com a 
ideia de que as redes sociais não combinam com atividades pedagógicas, evidenciando assim, reais possibilidades de uso.

Figura 2: Importância dos aspectos negativos do uso de redes sociais apontados pelos professores

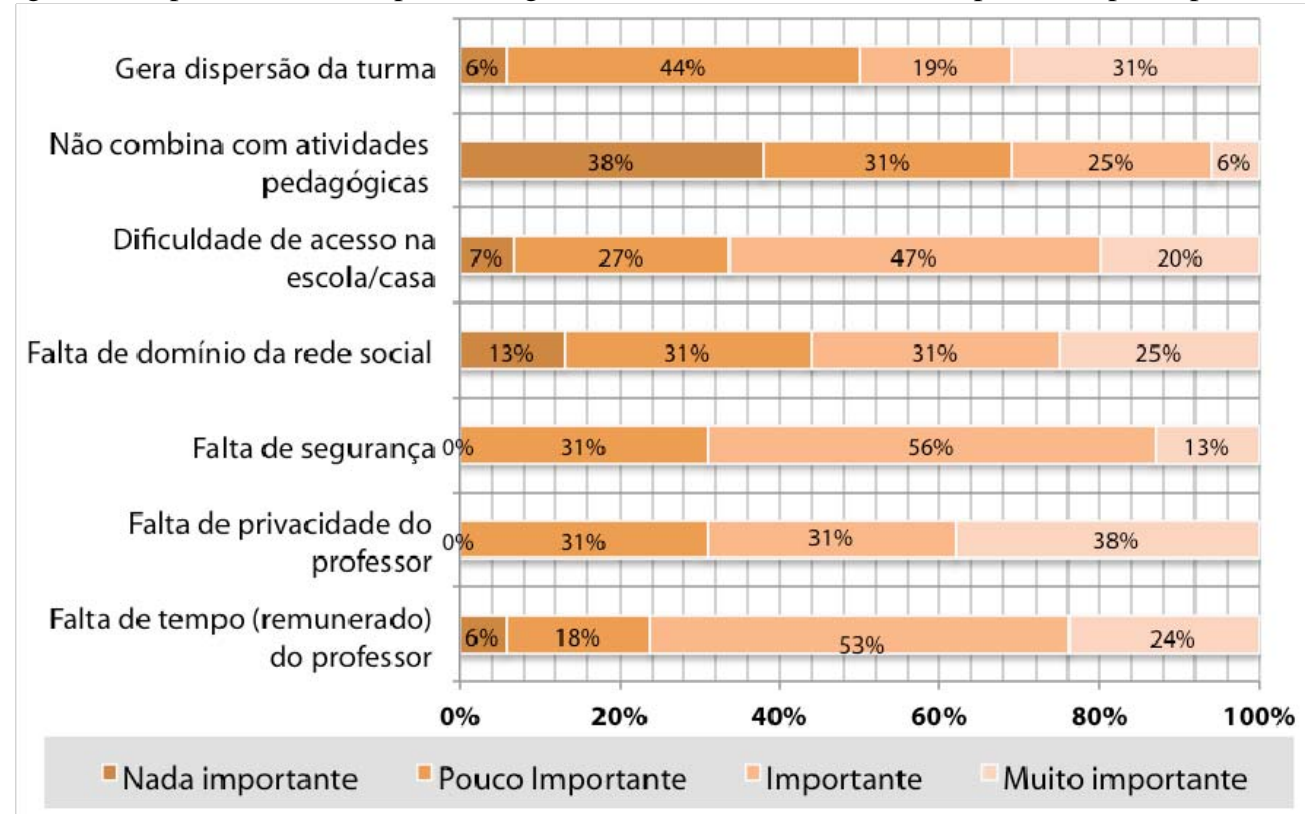

Por fim, em termos de limitações, foi questionada a possibilidade das redes sociais gerarem dispersão nas turmas, onde $50 \%$ dos professores acreditam nesta afirmativa.

Considerando aspectos que influenciam de forma positiva o uso de redes sociais na educação, todos os professores da região metropolitana de Porto Alegre, exceto dois, perfazendo 95\% deles, acredita que a facilidade de uso e acesso às redes sociais, assim como a diversidade de conteúdos disponíveis nas redes sociais, o fato das redes serem canais de comunicação muito utilizados pelos alunos e o fato das redes sociais terem acesso gratuito, sejam aspectos relevantes ou muito relevantes para o uso de redes sociais na educação.

Outro fator considerado relevante ou muito relevante por todos os professores, exceto um, é o fato das redes sociais trabalharem com diversos tipos de mídias.

Por fim, outros dois itens considerados relevantes ou muito relevantes para o uso de redes sociais na educação são o fato das redes sociais passarem uma imagem moderna do professor, com $76 \%$, e a possibilidade de fazer contatos com outras comunidades, com $87 \%$, conforme pode ser visto na Figura 3.

Ao serem questionados sobre suas experiências com o uso pedagógico das redes sociais, 39\% dos professores da região metropolitana de Porto Alegre afirmaram nunca ter usado as redes sociais com seus alunos e $45 \%$ já utilizou fazendo postagens individuais, enquanto $24 \%$ já usou as redes sociais criando grupos no Facebook e $13 \%$ criando páginas no Facebook.

De forma complementar, com o objetivo de permitir uma análise qualitativa, foram realizadas entrevistas semiestruturadas com alguns professores e diretores de escolas, escolhidos aleatoriamente em função do aceite em participar da investigação.

Podemos perceber, a partir das entrevistas, que a maioria dos professores não utiliza as redes sociais de forma educacional. Usam apenas como instrumento de comunicação, como um mural eletrônico.

Evidenciamos a existência de professores que se aproveitam da associação com seus alunos nas redes sociais para aproximarem-se deles, adicionando e aceitando seus alunos como "amigos" nas redes sociais, e outros que evitam isso, alegando falta de privacidade. 
Figura 3: Aspectos positivos do uso de redes sociais na educação apontados pelos professores

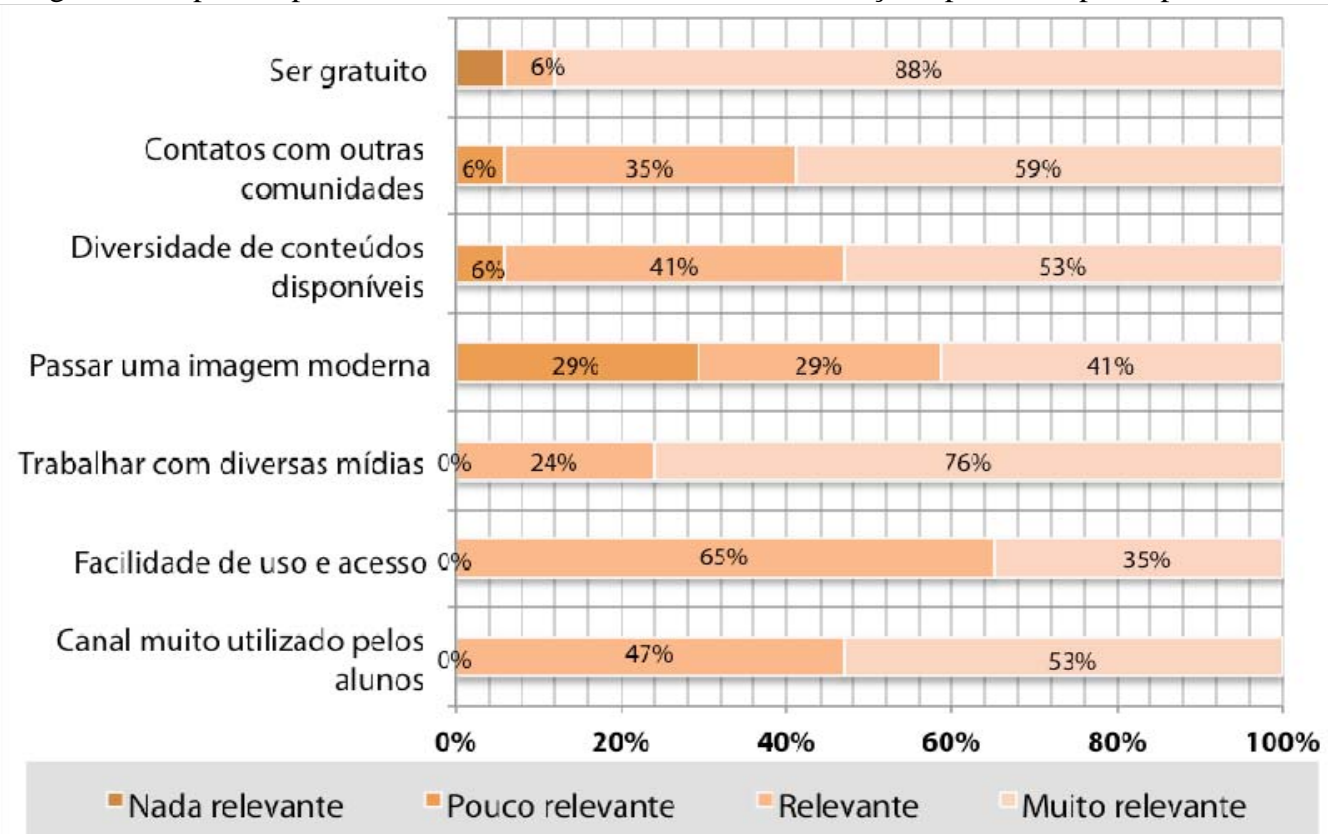

Dos aspectos positivos apontados pelos professores e diretores, destacamos o cibridismo (não colocado com esta palavra), mas o fato de permitir comunicação assíncrona e síncrona, dependendo da disponibilidade dos atores envolvidos.

Estes sujeitos pesquisados comentam que os alunos não sabem pesquisar e que as redes sociais geram dispersão, exigindo conscientização e mudança de postura por parte dos professores para melhor conduzir o uso destas tecnologias.

Os professores deixam transparecer, em suas respostas, que as ferramentas de redes sociais são boas e oferecem muitos recursos, porém, nem o professor, nem os alunos estão sabendo utilizar. E o uso, neste sentido, não é relacionado ao modo de operar as ferramentas, mas como aplicar as tecnologias para a educação.

Os professores reclamam que as redes sociais só são utilizadas pelos alunos para "socializar" coisas do seu cotidiano, enquanto poderiam ajudar a mudar essa cultura com exemplos contextualizados de suas disciplinas aos seus alunos e utilizando as redes também para fins educacionais.

Quando indagados sobre o motivo dos alunos não usarem as redes sociais para fins educacionais, somente para outras coisas, as opiniões são diversas, mas podem se complementar, apresentando, na maioria das vezes, o professor no centro desta solução.

Outra conclusão interessante que pode ser extraída é que, mesmo considerando-se escolas públicas - que tiveram maior representação critério de seleção - da região metropolitana de Porto Alegre, os índices de alunos e professores com acesso à internet e as redes sociais é superior às pesquisas globais apresentadas por Experian (2013) e Bannon (2012).

Pode ser evidenciado nesta pesquisa, a falta de infraestrutura das escolas para possibilitar o uso de redes sociais por seus alunos e professores, assim como a preocupação tanto dos professores quanto dos diretores das escolas, com questões relacionadas à segurança, privacidade e ética.

A percepção tanto dos professores, quanto dos diretores sobre o motivo deste não uso das redes sociais para educação, em contraponto ao uso maciço de redes sociais para comunicação e lazer, pode se resumir, principalmente, em uma questão cultural. Tanto em relação aos alunos quanto aos professores. E, por outro lado, o professor deve ser o principal motivador e exemplo dessa nova cultura que se estabelece, a cibercultura. 
Lévy (1999) comenta que o professor é incentivado a tornar-se um animador da inteligência coletiva de seus grupos de alunos em vez de um fornecedor direto de conhecimento.

O problema cultural é evidenciado também na pergunta sobre os tipos de mudanças importantes na escola e na sociedade para facilitar o uso de redes sociais na educação, feita tanto para os professores quanto para os diretores.

Na percepção dos professores e dos diretores, o principal motivo para o não uso de redes sociais na educação passa pela cultura tanto de alunos quanto de professores, e essa cultura pode ser trabalhada com formação/capacitação tanto dos professores quanto dos alunos.

Isso também pode ser evidenciado na pesquisa CETIC (2013), onde 64\% dos professores alegam ter aprendido a usar computador e internet sozinhos, e apenas $49 \%$ dos professores fizeram um curso específico, seguido por 38\% dos professores que aprenderam com outras pessoas (parentes ou amigos), 17\% com outro professor e $8 \%$ com os próprios alunos.

Soto (2009) já alerta para a necessidade de se ter um outro formato de educação no ciberespaço, onde temos diversidade de informação e fácil acesso a elas.

Quando indagados sobre as principais limitações ou desafios para o uso das redes sociais na educação, também evidenciamos o problema cultural, que conforme apontado pelos próprios sujeitos pesquisados, pode ser resolvido com capacitações e formação, corroborado com Castells (2003).

Quando a questão é verificar o que os sujeitos pensam a respeito das redes sociais combinarem com atividades pedagógicas, temos um consenso. $\mathrm{O}$ consenso de que as redes sociais combinam com atividades pedagógicas. Mas isso se contrapõe ao fato das redes sociais não serem utilizadas como atividades pedagógicas.

Essas opiniões mostram que os professores concordam com as possibilidades pedagógicas das redes sociais, contudo, também concordam que faltam investimentos nos professores, de forma a capacitá-los para o uso dessas novas tecnologias.

Diversos professores relacionam a dispersão com a técnica ou o conteúdo inadequado para as tecnologias de redes sociais.

O Professor \#3 fez uma reflexão que corrobora com o conceito de rede, de cibercultura, da inteligência coletiva de Lévy (1998 e 1999) e da analogia do rizoma de Deleuze e Guattari (1995a), quando diz: "A dispersão é uma forma de estabelecer links, conexões entre diversos conhecimentos".

Ou seja, a dispersão existe nas redes sociais e sempre existiu na escola, no trabalho, na residência, em todos os lugares. Contudo, ela pode ser vista como uma forma de estabelecer links com outros mundos, com outras redes, outros rizomas.

\section{Conclusões}

Mesmo frente ao massivo uso de redes sociais, concluímos a partir desta investigação, que no presente momento, o cenário do uso de redes sociais para fins educacionais na região metropolitana de Porto Alegre/RS é inexpressivo, contudo, de grande potencial.

Para ampliar o uso educacional das redes sociais, devemos vencer alguns obstáculos e considerar as preocupações apresentadas tanto pelos diretores quanto pelos professores das escolas, sob a luz da experiência de pesquisadores e empresas que já fizeram tal uso, sabendo que dadas as características dinâmicas das redes sociais, nunca teremos soluções prescritivas ou o esgotamento do assunto, e sim, reflexões que buscam colaborar para apontar possibilidades pedagógicas do uso de redes sociais. 
Os sujeitos pesquisados apontaram alguns aspectos importantes na escolha da rede social, como privacidade, segurança, possibilidade de conexões externas, multimídia, multiplataforma, facilidade de uso, valor monetário, funcionalidades, capacidade de integração e evolução, popularidade e aplicativos existentes que possam ampliar as potencialidades.

Em termos de formas de uso das redes sociais, os sujeitos apontaram para as possibilidades de uso de grupos de estudos, disponibilização de conteúdos extras e bons exemplos para os alunos, discussões, calendários de eventos, bate-papos para tirar dúvidas e enquetes.

Quanto aos cuidados ao acessar as redes sociais, observou-se a importância de definir e pactuar com alunos, professores e direção, uma espécie de código de conduta, ou 'as regras do jogo', deixando claro, inclusive, que esse código de conduta pode ir se adaptando e evoluindo no decorrer da vida do grupo, em função de necessidades que poderão surgir.

Em termos de funcionalidades das redes sociais na educação, foi sugerido pelos sujeitos: comunicar e interagir com os outros através de mensagens (privadas, em grupos, em páginas e no mural de amigos), comunicação por chat, cutucar e curtir, perguntar e criar grupos; compartilhamento de links e recursos; discussão de temas de interesse; construção conjunta de documentos e organização e divulgação de eventos.

Em relação a aspectos socioculturais, pode-se concluir que a gratuidade do serviço de acesso às redes sociais, a possibilidade de ampliar a inclusão social, a possibilidade de integração e trocas culturais, o intercambio de informações, a construção colaborativa de conhecimentos e a ciberdemocracia ou a igualdade digital, são fatores que potencializam o uso educacional das redes sociais.

Resumidamente, os professores acreditam que as redes sociais estão a cada dia sendo mais utilizadas pelos alunos, e que isso não tem volta. Os professores e diretores sabem dos potenciais das ferramentas de redes sociais, assim como dos principais problemas, que não são causados pelas redes sociais, mas podem ser potencializados por elas.

Eles acreditam que as redes sociais sejam boas ferramentas, precisando de mudanças culturais para sua melhor utilização, e para ocorrem essas mudanças, fazemse necessários, dentre outras coisas, investimentos em capacitação/formação tanto de professores quanto de alunos.

Autores como Patrício e Gonçalves (2010) e Martín-Moreno (2004) também concluem, em suas pesquisas, que o uso das redes sociais com alunos deve trazer pontos positivos como o aumento do interesse, motivação, participação, colaboração e interação dos alunos com os conteúdos, com a professora e com os colegas.

\section{Bibliografia}

ANDRADE, P.; AZEVEDO, D.; DÉDA, T. Práticas de Ensinagem e Redes Sociais na Internet: um estudo de caso do Facebook como ambiente de aprendizagem. $\mathbf{3}^{\mathbf{0}}$ Simpósio Educação e Comunicação - infoinclusão: possibilidades de ensinar e aprender. GECES - UNIT. Sergipe, 2012.

BARBOSA, A. F. (coord.) Pesquisa sobre o uso das tecnologias da informação e comunicação no Brasil. [livro eletrônico]: TIC Domicílios e Empresas 2012. São Paulo: Comitê Gestor da Internet no Brasil, 2013. Disponível em: <www.cetic.br/publicacoes/2012/tic-domicilios-2012.pdf> . Acesso em dezembro 2013. CASTELLS, M. A sociedade em rede. Volume 1. Rio de Janeiro: Paz e Terra, 1999. . A galáxia da internet: reflexões sobre a internet, os negócios e a sociedade. Rio de Janeiro: Jorge Zahar, 2003. 
DEGENNE, A.; FORSÉ, M. Introducing Social Networks. London: Sage, 1999. DONATH, J. S. Identity and Deception in the Virtual Community. In: KOLLOCK, Peter e SMITH, Marc (org.). Communities in Cyberspace. New York: Routledge, 1999.

FRANCO, A. Topologias de Rede. Texto publicado em “Cartas de Rede Social 168”, 17 de julho de 2008.

GABRIEL, M. Educ@r: a (r)evolução digital na educação. São Paulo: Saraiva Editora, 2013.

IBOPE. Almanaque IBOPE. Disponível em:

<www.almanaqueibope.com.br/asp/busca_docInfo.asp>. Acesso em dezembro de 2011. LEMOS, A; LÉVY, P. O futuro da internet: em direção a uma ciberdemocracia planetária. São Paulo: Paulus, 2010.

LEMOS, A. Cibercultura: tecnologia e vida social na cultura contemporânea. Porto Alegre: Sulina, 2002.

LÉVY, P. A inteligência coletiva: por uma antropologia do ciberespaço. $2^{\mathrm{a}}$ ed. São Paulo: Loyola, 1998.

. Cibercultura. Rio de Janeiro, Editora 34, 1999.

. O que é o virtual? Tradução de Paulo Neves. São Paulo: Ed. 34, 1996.

LLORENS, F.; CAPDEFERRO, N. Posibilidades de la plataforma Facebook para el aprendizaje en línea. Revista de Universidad y Sociedad del Conocimiento (RUSC), vol. 8, n.2, p.31-45. Julho, 2011.

MACHADO, J. R.; TIJIBOY, A. V. Redes Sociais Virtuais: um espaço para efetivação da aprendizagem cooperativa. CINTED/UFRGS: Novas Tecnologias na Educação vol. 3 - n.1 - maio, 2005.

MAZMAN, S. G.; USLUEL, Y. K. The Usage of Social Networks in Educational Context. World Academy of Science, Engineering and Technology, V.25, 26/01/2009.

PATRICIO, M. ; GONÇALVES, V. Utilização educativa do Facebook no Ensino Superior. Universidade de Évora, 2010 a.

. Facebook: rede social educativa? In: I Encontro Internacional TIC e Educação. Lisboa: Universidade de Lisboa/ Instituto de Educação, 2010 b. p. 593-598. PECHI, D. Como usar as redes sociais a favor da aprendizagem. Revista Escola, Outubro/2011 p. 10-13. São Paulo: Abril, 2011.

PRETTO, Nelson De Luca; ANDRADES, Simony Alves de. A internet e o desafio para os professores. Revista Acesso v.16, p.31-38. São Paulo, 2002.

RECUERO, R. Redes Sociais na Internet. Porto Alegre: Sulina, 2009.

. b. Mapeando redes sociais na Internet através da conversação mediada pelo computador. HETKOWSKI, Tania Maria; NASCIMENTO, Antônio Dias (Org.). Educação e Contemporaneidade: pesquisas científicas e tecnológicas. Salvador: EDUFBA, 2009.

WERHMULLER, C. M.; SILVEIRA, I. F. Redes sociais como ferramentas de apoio à educação. Anais do II Seminário Hispano Brasileiro - CTS, p. 594 - 605, 2012. 